\title{
Corrigendum to "Oscillation behavior of third- order neutral Emden-Fowler delay xdynamic equations on time scales" [Adv. Difference Equ., 2010, 1-23 (2010)]
}

Tao Ji ${ }^{1}$, Shuhong Tang ${ }^{1}$ and Tongxing $\mathrm{Li}^{2,33^{*}}$

* Correspondence: litongx2007@163.com

${ }^{2}$ School of Control Science and Engineering, Shandong University, Jinan, Shandong 250061, P. R. China

Full list of author information is available at the end of the article

\section{Abstract}

In this article, we revise results obtained by Han et al.

Mathematics Subject Classification 2000: 34K11; 39A10.

Keywords: oscillation, third-order, neutral dynamic equation, time scale

\section{Introduction}

Emden-Fowler type dynamic equations have some applications in the real world; see the background details introduced by Hilger [1]. Hence [2] studied a class of thirdorder Emden- Fowler neutral dynamic equations

$$
\left(r(t)(x(t)-a(t) x(\tau(t)))^{\Delta^{2}}\right)^{\Delta}+p(t) x^{\gamma}(\delta(t))=0
$$

on a time scale $\mathbb{T}$ with sup $\mathbb{T}=\infty$, where the authors assume the following hypotheses hold.

$\left(A_{1}\right) \gamma>0$ is the quotient of odd positive integers;

$\left(A_{2}\right) r$ and $p$ are positive real-valued rd-continuous functions defined on $\mathbb{T}$ such that $r^{\Delta}(t) \geq 0$;

$\left(A_{3}\right) a$ is a positive real-valued rd-continuous function defined on $\mathbb{T}$ such that $0<a$

$(t) \leq a_{0}<1$ and $\lim _{t \rightarrow \infty} a(t)=a_{1}$;

$\left(A_{4}\right)$ the functions $\tau: \mathbb{T} \rightarrow \mathbb{T}$ and $\delta: \mathbb{T} \rightarrow \mathbb{T}$ are rd-continuous functions such that $\tau(t) \leq t, \delta(t) \leq t$, and $\lim _{t \rightarrow \infty} \tau(t)=\lim _{t \rightarrow \infty} \delta(t)=\infty$.

A time scale $\mathbb{T}$ is an arbitrary nonempty closed subset of the real numbers $\mathbb{R}$. Since we are interested in oscillatory behavior, we suppose that the time scale under consideration is not bounded above and is a time scale interval of the form $\left[t_{0}, \infty\right)_{\mathbb{T}}:=\left[t_{0}, \infty\right) \cap \mathbb{T}$. For some concepts related to the notion of time scales; see [3]. Regarding the oscillation properties of (1.1) with $a(t)=0$, Saker [4-7] established some types of criteria, e.g., Hille-Nehari-type and Philos-type.

(C) $2012 \mathrm{Ji}$ et al; licensee Springer. This is an Open Access article distributed under the terms of the Creative Commons Attribution License (http://creativecommons.org/licenses/by/2.0), which permits unrestricted use, distribution, and reproduction in any medium, provided the original work is properly cited. 
To establish oscillation criteria for (1.1), [2] obtained various oscillation theorems by using some lemmas, one of which we present below for the convenience of the reader.

Lemma 1.1. (See [2, Lemma 2.1]). Let $z(t):=x(t)-a(t) x(\tau(t))$. Assume that $\left(A_{1}\right)-\left(A_{4}\right)$ hold and

(H) there exists $\left\{c_{k}\right\}_{k \in \mathbb{N}_{0}} \subset \mathbb{T}$ such that $\lim _{k \rightarrow \infty} c_{k}=\infty$ and $\tau\left(c_{k+1}\right)=c_{k}$.

Assume also that $x$ is an eventually positive solution of (1.1). If

$$
\int_{t_{0}}^{\infty} \frac{\Delta t}{r(t)}=\infty
$$

then there are only the following three cases for $t \in\left[t_{1}, \infty\right)_{\mathbb{T}}$, where $t_{1} \in\left[t_{0}, \infty\right)_{\mathbb{T}}$ sufficiently large:

Case $(i) \cdot z(t)>0, z^{\Delta}(t)>0, z^{\Delta^{2}}(t)>0, z^{\Delta^{3}}(t)<0$;

Case (ii). $z(t)>0, z^{\Delta}(t)>0, z^{\Delta^{2}}(t)>0, z^{\Delta^{3}}(t)<0 ; \lim _{t \rightarrow \infty} x(t)=0$;

Case

$$
z(t)>0, z^{\Delta}(t)<0, z^{\Delta^{2}}(t)>0, z^{\Delta^{3}}(t)<0, \lim _{t \rightarrow \infty} z(t)=l \geq 0, \lim _{t \rightarrow \infty} x(t)=l /(1-a) \geq 0 .
$$

We note that there exists a mistake in the above statements. First, the case (ii) does not occur since $z^{\Delta}>0$ and $z^{\Delta^{2}}>0$ imply that $\lim _{t \rightarrow \infty} z(t)=\infty$, and so $z>0$ eventually. Second, the restrictive assumption $(H)$ can be omitted. Hence the purpose of this article is to revise the related results in [2].

\section{Revised results}

Now we use notation $z$ as in Lemma 1.1 and present the following new lemmas.

Lemma 2.1. Let (1.2), $\left(A_{1}\right),\left(A_{2}\right)$, and $\left(A_{4}\right)$ hold with $\left(A_{3}\right)$ replaced by $\left(A 3^{*}\right) a$ is a positive real-valued rd-continuous function defined on $\mathbb{T}$

such that $0<a(t) \leq a_{0}<1$. Suppose that $x$ is an eventually positive solution of (1.1). Then there are only the following three cases eventually:

$$
\begin{aligned}
& \text { Case (1). } z>0, z^{\Delta}>0, z^{\Delta^{2}}>0,\left(r z^{\Delta^{2}}\right)^{\Delta}<0 \\
& \text { Case (2). } z>0, z^{\Delta}<0, z^{\Delta^{2}}>0,\left(r z^{\Delta^{2}}\right)^{\Delta}<0 \\
& \text { Case (3). } z<0, z^{\Delta}<0, z^{\Delta^{2}}>0,\left(r z^{\Delta^{2}}\right)^{\Delta}<0 .
\end{aligned}
$$

Proof. Assume that $x$ is an eventually positive solution of (1.1). Then, we have by (1.1) that $\left(r z^{\Delta^{2}}\right)^{\Delta}<0$, and hence $r z^{\Delta^{2}}$ is decreasing and of one sign. The condition $r z^{\Delta^{2}}<0$ implies that there exist a $t_{1} \in\left[t_{0}, \infty\right)_{\mathbb{T}}$ and a constant $M>0$ such that

$$
r(t) z^{\Delta^{2}}(t) \leq-M, \text { for } t \in\left[t_{1}, \infty\right)_{\mathbb{T}}
$$

which yields

$$
z^{\Delta^{2}}(t) \leq-\frac{M}{r(t)}, \text { for } t \in\left[t_{1}, \infty\right)_{\mathbb{T}}
$$


Integrating from $t_{1}$ to $t$ and letting $t \rightarrow \infty$, we have by (1.2) that

$$
\lim _{t \rightarrow \infty} z^{\Delta}(t)=-\infty
$$

Hence there exist a $t_{2} \in\left[t_{1}, \infty\right)_{\mathbb{T}}$ and a constant $M_{1}>0$ such that

$$
z^{\Delta}(t) \leq-M_{1}, \text { fort } \in\left[t_{2}, \infty\right)_{\mathbb{T}}
$$

Integrating the above inequality from $t_{2}$ to $t$ and letting $t \rightarrow \infty$, we have

$$
\lim _{t \rightarrow \infty} z(t)=-\infty
$$

which yields $z<0$ eventually. Then, we get

$$
z<0, z^{\Delta}<0, z^{\Delta^{2}}<0,\left(r z^{\Delta^{2}}\right)^{\Delta}<0
$$

From (2.1) we have that $\lim _{t \rightarrow \infty} z(t)=-\infty$. Next we claim that $x$ is bounded and (2.1) does not occur. If not, there exists a sequence $\left\{t_{m}\right\}_{m \in \mathbb{N}} \in\left[t_{0}, \infty\right)_{\mathbb{T}}$ with $t_{m} \rightarrow \infty$ as $m \rightarrow$ $\infty$ such that

$$
x\left(t_{m}\right)=\max \left\{x(s): t_{0} \leq s \leq t_{m}\right\} \text { and } \lim _{m \rightarrow \infty} x\left(t_{m}\right)=\infty .
$$

It follows from $\tau(t) \leq t$ that

$$
z\left(t_{m}\right)=x\left(t_{m}\right)-a\left(t_{m}\right) x\left(\tau\left(t_{m}\right)\right) \geq\left(1-a_{0}\right) x\left(t_{m}\right),
$$

which implies that $\lim _{m \rightarrow \infty} z\left(t_{m}\right)=\infty$, this contradicts the fact that $\lim _{t \rightarrow \infty} z(t)=-\infty$. Hence $x$ is bounded, and so (2.1) does not hold.

If $z^{\Delta}>0$ and $z^{\Delta^{2}}>0$, then $z>0$. Thus, for $z^{\Delta^{2}}>0$ only the cases (1), (2), and (3) may occur. The proof is complete.

Lemma 2.2. Let $0<a(t) \leq a_{0}<1$. If case (3) holds, then $\lim _{t \rightarrow \infty} x(t)=0$.

Proof. Assume that (3) holds. Then $\lim _{t \rightarrow \infty} z(t) \leq 0$. Next we claim that $x$ is bounded. Similar as in the proof of Lemma 2.1 , we have that $\lim _{m \rightarrow \infty} z\left(t_{m}\right)=\infty$ which contradicts the fact that $\lim _{t \rightarrow \infty} z(t) \leq 0$. Thus, $x$ is bounded. Hence we can suppose that $\lim$ $\sup _{t \rightarrow \infty} x(t)=x_{1}$, where $0 \leq x_{1}<\infty$. Then, there exists a sequence $\left\{t_{k}\right\}_{k \in \mathbb{N}} \in\left[t_{0}, \infty\right)_{\mathbb{T}}$ with $t_{k} \rightarrow \infty$ as $k \rightarrow \infty$ such that $\lim _{k \rightarrow \infty} x\left(t_{k}\right)=x_{1}$. Next we show that $\lim _{t \rightarrow \infty} x(t)=0$. If not, then $x_{1}>0$. Pick $\varepsilon=x_{1}\left(1-a_{0}\right) /\left(2 a_{0}\right)$, we find that $x\left(\tau\left(t_{k}\right)\right)<x_{1}+\varepsilon$ eventually. Moreover,

$$
0=\lim _{k \rightarrow \infty} z\left(t_{k}\right) \geq \lim _{k \rightarrow \infty}\left(x\left(t_{k}\right)-a_{0}\left(x_{1}+\varepsilon\right)\right)=\frac{x_{1}\left(1-a_{0}\right)}{2}>0 .
$$

This is a contradiction. The proof is complete.

\section{Discussions}

In this article, we establish Lemmas 2.1 and 2.2 which improve Lemma 1.1 used in [2]. Using these lemmas and methods given in [2,4-7], one can renew those results of [2] and present some other new results. In particular, new results only require that $0<a$ $(t) \leq a_{0}<1$ rather than $(H), 0<a(t) \leq a_{0}<1$, and $\lim _{t \rightarrow \infty} a(t)=a_{1}$. The details are left to the reader.

To achieve new results, we are forced to require that $0<a(t) \leq a_{0}<1$. The question regarding the oscillatory properties of (1.1) without this assumption remains open at the moment. 


\section{Acknowledgements}

The authors express their sincere gratitude to the Editor and anonymous referees for careful reading of the original manuscript and useful comments that helped to improve presentation of results and accentuate important details. T. Li would like to express their gratitude to Professors Ravi P. Agarwal and Martin Bohner for their kindly guidance. This research is supported by Natural Science Foundation of Shandong Province (Z2007F08) and also by Weifang University Research Funds for Doctors (2012BS25).

\section{Author details}

${ }^{1}$ School of Information and Control Engineering, Weifang University, Weifang, Shandong 261061, P. R. China ${ }^{2}$ School of Control Science and Engineering, Shandong University, Jinan, Shandong 250061, P. R. China ${ }^{3}$ School of Mathematical Sciences, University of Jinan, Jinan, Shandong 250022, P. R. China

\section{Authors' contributions}

TJ and ST framed and solved the problem. TL modified and made necessary changes in the proof of the results. All authors read and approved the final manuscript.

\section{Competing interests}

The authors declared that they have no competing interests.

Received: 24 October 2011 Accepted: 9 May 2012 Published: 9 May 2012

\section{References}

1. Hilger, S: Analysis on measure chains-a unified approach to continuous and discrete calculus. Results Math. 18, 18-56 (1990)

2. Han, Z, Li, T, Sun, S, Zhang, C: Oscillation behavior of third-order neutral Emden-Fowler delay dynamic equations on time scales. Adv Difference Equ. 2010, 1-23 (2010)

3. Bohner, M, Peterson, A: Dynamic Equations on Time Scales: An Introduction with Applications. Birkhäuser, Boston (2001)

4. Kubiaczyk, I, Saker, SH: Asymptotic properties of third order functional dynamic equations on time scales. Ann Pol Math. 100, 203-222 (2011). doi:10.4064/ap100-3-1

5. Saker, SH: Oscillation of third-order functional dynamic equations on time scales. Sci China Math. 54, 2597-2614 (2011). doi:10.1007/s11425-011-4304-8

6. Saker, SH: On oscillation of a certain class of third-order nonlinear functional dynamic equations on time scales. Bull Math Soc Sci Math Roumanie Tome. 54, 365-389 (2011)

7. Saker, SH: Oscillation Theory of Dynamic Equations on Time Scales: Second and Third Orders. Lambert Academic Publishing, Germany (2010)

doi:10.1186/1687-1847-2012-57

Cite this article as: Ji et al:: Corrigendum to "Oscillation behavior of third-order neutral Emden-Fowler delay xdynamic equations on time scales" [Adv. Difference Equ., 2010, 1-23 (2010)]. Advances in Difference Equations 2012 2012:57.

\section{Submit your manuscript to a SpringerOpen ${ }^{\circ}$ journal and benefit from:}

Convenient online submission

- Rigorous peer review

- Immediate publication on acceptance

- Open access: articles freely available online

- High visibility within the field

- Retaining the copyright to your article

Submit your next manuscript at $\gg$ springeropen.com 